\title{
Antisépticos orales en la reducción de la carga viral del SARS- COV-2 en la consulta odontológica
}

\author{
Oral antiseptics in the reduction of viral load of SARS-COV-2 in dental \\ consultation
}

\author{
Shirley Suley Guerra-Robalino (1] 1,a, Lizbeth Milagros Brañes Huamán (i] 1,a , Brenda Anait Domínguez-Calle (이 1,a, \\ Manuel Antonio Mattos-Vela (ib) 1,b
}

\section{RESUMEN}

El incremento de contagios por COVID-19 a nivel mundial y la susceptibilidad en la que se encuentra el odontólogo, debido al contacto cercano con la saliva de los pacientes y la producción de aerosoles portadores de SARS-CoV-2, ha generado la búsqueda de nuevas medidas preventivas con la intención de reducir el riesgo presente en el consultorio dental. Recientes investigaciones, basadas en la actividad antiviral que presentan algunos antisépticos orales, tales como: clorhexidina, povidona yodada, cloruro de cetilpiridinio y peróxido de hidrógeno; se han centrado en evaluar la eficacia que pudiesen tener estas distintas soluciones frente al nuevo virus en medios similares a la cavidad oral. En base a ello, el presente artículo tuvo el objetivo de realizar una revisión sobre la eficacia antiviral de los enjuagues bucales sobre el SARS-CoV-2 como medida preventiva ante el riesgo de transmisión en la consulta odontológica. Se realizó una búsqueda de artículos originales pertinentes al tema, las bases de datos fueron Medline y Scopus; bibliotecas electrónicas: SciELO, WILEY, y buscadores académicos como Google académico. En cuanto a los resultados, la yodopovidona ha demostrado una eficacia superior contra el COVID-19 seguidas del peróxido de hidrógeno, cloruro de cetilpiridinio y clorhexidina. Si bien los estudios clínicos con respecto a la duración de eficacia en la cavidad oral son limitados, se concluyó que los enjuagues bucales parecen ser una buena opción preventiva, segura y complementaria en la práctica odontológica; mientras se está a la espera de terapias más eficaces o de una vacuna.

Palabras clave: COVID-19; Enjuagues bucales; Odontología; Saliva; Antiviral. (Fuente: DeCSBIREME)

\section{ABSTRACT}

The increase in COVID-19 infections worldwide and the susceptibility of the dental professionals due to close contact with patients' saliva and the production of aerosols carrying SARS-CoV-2, has generated the search for new preventive measures with the intention of reducing the risk present in the dental office. Recent research, based on the antiviral activity of some oral antiseptics, such as: chlorhexidine, povidone iodide, cetylpyridinium chloride and hydrogen peroxide; have focused on evaluating the efficacy that these different solutions might have against the new virus in media similar to the oral cavity. Based on this, this article has the objective of conducting a review on the antiviral efficacy of mouth rinses on SARS-CoV-2 as a preventive measure against the risk of transmission in the dental office. A search was made for original articles relevant to the topic, the databases were Medline and Scopus; electronic libraries: SciELO, WILEY, and academic search engines such as Google Scholar. In terms of results, iodopovidone has been shown to be more effective against COVID-19 followed by hydrogen peroxide, cetylpyridinium chloride and chlorhexidine. While clinical studies regarding the duration of efficacy in the oral cavity are limited, it was concluded that mouthwashes appear to be a good preventive, safe and a complementary option in dental practice; while awaiting more effective therapies or a vaccine.

Keywords: COVID-19; Mouthwashes; Dentistry; Saliva; Antivir. (Source: MeSH NLM)

1. Universidad Nacional Mayor de San Marcos, Facultad de Odontología. Lima, Perú

a. Estudiante de Odontología.

. Doctor en Estomatología. Docente asociado

Correspondencia:

Shirley Guerra Robalino

Correo electrónico: shirley.guerra@unmsm.edu.pe
Este es un artículo de acceso abierto distribuido bajo la licencia Creative Commons Atribución 4.0 Internacional (CC BY 4.0)

https://creativecommons.org/licenses/by/4.0/deed.es

Citar como: Guerra Robalino SS, Brañes Huamán LM, Domínguez Calle BA, Mattos Vela MA. Antisépticos orales en la reducción de la carga viral del SARS-COV-2 en la consulta odontológica. KIRU. 2021;18(3):178-186. https://doi.org/10.24265/kiru. 2021.v18n3.07. 


\section{INTRODUCCIÓN}

EI COVID-19 es una enfermedad sumamente contagiosa, causada por el virus SARS-CoV-2, que ha incrementado exponencialmente el número de infectados en un corto periodo de tiempo, es así que la Organización Mundial de la Salud (OMS), hasta la actualidad, ha notificado más de 84 millones de casos confirmados, incluidas 1,848,704 muertes a nivel mundial ${ }^{(1)}$.

La patogenicidad de este virus se debe a que se encuentra rodeado por una envoltura lipídica, que cubre su genoma de ARN, adquiridas del retículo endoplasmático rugoso y del aparato de Golgi de las células infectadas. Es en esta envoltura, donde se insertan las glicoproteínas en forma de punta, quienes son las responsables de inducir respuestas celulares inmunitarias en el huésped ${ }^{(2)(3)}$. Estas glicoproteínas presentan gran afinidad por los receptores de la enzima convertidora de angiotensina 2 (ACE2) que se encuentran en las células epiteliales de las glándulas salivales $(4,5)$. Esto explica por qué la saliva es considerada una de las principales fuentes de contagio del SARS-CoV-2 (6) que, desde su aparición en el 2019 en Wuhan, China y su rápida propagación en diversos países, ha cambiado drásticamente la vida en la sociedad.

De manera que, la población a nivel mundial se ha visto en la necesidad de optar por medidas preventivas con el fin de disminuir y/o frenar su propagación; siendo la odontología una de las profesiones que no se encuentra ajena a esta situación debido al gran riesgo de contagio por la cercanía constante con la saliva de los pacientes y la producción de aerosoles dentro del consultorio dental (7). Por ello, a fin de reducir la contaminación cruzada en la consulta dental, se viene considerando el uso de enjuagues bucales previo a los procedimientos dentales con la finalidad de disminuir la cantidad de microorganismos presentes en la cavidad oral, incluido el virus del SARS-CoV-2 (3)

En un estudio, evaluaron la eficacia de tres enjuagues bucales: povidona yodada (PVP-I), gluconato de clorhexidina $(\mathrm{CHX})$ y cloruro de cetilpiridinio (CPC), con la finalidad de demostrar su capacidad reductora de la carga viral salival del SARS-CoV-2 en pacientes diagnosticados con COVID-19. Los resultados evidenciaron que enjuagues bucales como
CPC y PVP-I tienen un efecto sostenido en la reducción de la carga viral en saliva en comparación con las muestras de control ${ }^{(8)}$. Otro estudio con características similares, probó la actividad viricida de ocho enjuagues bucales que contienen diferentes compuestos activos contra tres diferentes aislados de SARS-CoV-2 en condiciones que imitan las secreciones nasofaríngeas. Los resultados arrojaron que tres de las ocho formulaciones, incluido cloruro de decualinio, PVP-I y etanol aceites esenciales, redujeron significativamente la infectividad viral del SARS-CoV-2 en un tiempo de exposición de 30 segundos ${ }^{(9)}$.

Las presentes publicaciones mencionadas revelan la capacidad que poseen ciertos enjuagues bucales para inactivar al virus en un corto tiempo de exposición. Estos significativos resultados podrían proporcionar el fundamento necesario para que los enjuagues bucales, que demostraron eficacia, sean incorporados a protocolos de bioseguridad a utilizarse en una intervención odontológica, teniendo en cuenta que uno de los principales enfoques para minimizar el riesgo de transmisión de COVID19 sería reducir los títulos de SARS-CoV-2 en la saliva de pacientes infectados.

Hasta la fecha, no existe cura para combatir el virus SARS-Cov-2, lentamente se vienen realizando pruebas específicas de control y prevención; no obstante, la información sobre el tema aún sigue siendo limitada y escasa; en especial, estudios in vivo en pacientes portadores del virus. Por lo tanto, el objetivo del presente artículo es realizar una revisión sobre la eficacia antiviral de los enjuagues bucales sobre el SARS-CoV-2 como medida preventiva ante el riesgo de transmisión en la consulta odontológica.

\section{METODOLOGÍA}

Se realizó la búsqueda electrónica de información utilizando la base de datos en salud: Medline, a través de Pubmed; base de datos multidisciplinares como Scopus; bibliotecas electrónicas: SciELO, WILEY, y buscadores académicos como Google académico. La búsqueda de información científica utilizó los siguientes descriptores $\mathrm{MeSH}$ (Medical Subject Headings): "SARSCoV-2", "COVID-19" "Viral Load", "Mouthwashes", "Hydrogen Peroxide", "Chlorhexidine", "Povidone-lodine", "Cetylpyridinium Chloride". La recolección de 
artículos se realizó de enero a diciembre del 2020.

Para la selección, se tomó en cuenta artículos originales in vivo $\mathrm{e}$ in vitro $\mathrm{y}$, en menor proporción, artículos de revisión; sin embargo, teniendo en cuenta la limitación de estudios pertinentes al tema de investigación, no se impusieron restricciones en cuanto al idioma y la fecha de publicación de los artículos en los recursos encontrados.

\section{Mecanismos de transmisión en el consultorio dental}

Existen dos formas de contagio más frecuentes que se dan a nivel mundial y con mayor riesgo en la práctica odontológica. La primera se da a través de las vías respiratorias, que comienza cuando una persona infectada con SARS-CoV2 libera gotas al momento de toser, estornudar o hablar. Este tipo de contagio no involucra un contacto directo $y$ es necesario que se encuentre como máximo a dos metros de distancia para que el receptor pueda contagiarse al inhalar las gotas portadoras del virus ${ }^{(10-12)}$

La segunda forma es por el contacto directo con saliva, secreciones nasofaríngeas y oculares provenientes de personas infectadas $(11,4)$; sin embargo, aún existen dudas con respecto a la presencia del virus en fluidos oculares. En un estudio realizado por Xia et al., se evaluó la presencia del nuevo coronavirus en lágrimas y secreciones conjuntivales de pacientes infectados con el SARS-CoV-2. Los resultados indicaron que, de los 21 pacientes, solo uno con conjuntivitis arrojó resultados positivos en el análisis de reacción en cadena de la polimerasa con transcripción inversa (RT PCR) ${ }^{(13)}$.

Es así que la propagación del coronavirus no está ausente en la práctica odontológica (14). Distintos procedimientos dentales que, comúnmente utilizan instrumental rotatorio, raspadores ultrasónicos, jeringas de aire-agua y turbinas de aire, provocan la liberación de aerosoles y gotitas que pueden estar contaminadas con el virus de un paciente con SARS-CoV-2, sumado a ello, la existencia de casos asintomáticos con capacidad de transmitir el virus, elevan aún más este riesgo de infección ${ }^{(15,16)}$.

Estos aerosoles generados están compuestos de partículas líquidas y sólidas (menos de 50 $\mu \mathrm{m}$ de diámetro) y cuando el líquido se evapora, las partículas sólidas forman núcleos de gotitas de 0,5 a $10 \mu \mathrm{m}$ compuestos por saliva, suero seco y microorganismos ${ }^{(17)}$. La inhalación de estas partículas aerotransportadas durante los tratamientos dentales puede llegar a penetrar el sistema respiratorio, transmitiendo así diversas enfermedades infecciosas como el SARS-CoV2; incluso se ha registrado que pueden permanecer a flote en el aire durante varias horas ${ }^{(18)}$.

Otra forma de transmisión del SARS-CoV-2, dentro del consultorio dental, es mediante un contacto indirecto, a través, de instrumentos y/o superficies contaminadas que, en muchas ocasiones, se originan por los aerosoles 0 gotas mezcladas con la saliva de algún paciente infectado, las cuales han quedado suspendidas en el aire durante un tiempo prolongado y tienden a asentarse en alguna superficie del consultorio (4). Es importante tener en cuenta esta información debido a que la OMS afirma que el virus del SARS-CoV-2 mantiene su infectividad en superficies de plástico, vidrio y acero inoxidable hasta $72 \mathrm{~h}$, en superficies de cobre hasta $4 \mathrm{~h}$ y en superficies de cartón hasta $24 \mathrm{~h}$ a temperatura ambiente; pero si se incrementa la temperatura, superior a los $30^{\circ} \mathrm{C}$, la persistencia del virus puede disminuir $(19,20)$. Por lo tanto, la contaminación de las superficies e instrumentos, dentro del consultorio dental, es una fuente potencial de transmisión del virus SARS-CoV-2; en base a ello, se recomienda la utilización de agentes biocidas para su desinfección ${ }^{(18)}$.

Este ambiente producido durante los tratamientos dentales obliga a los odontólogos a estar inminentemente expuestos al virus. Ello incentiva al aumento del uso de barreras de bioseguridad y a la implementación de nuevas medidas y protocolos de atención en pacientes considerados siempre potencialmente infecciosos.

\section{Principales antisépticos orales}

\section{Yodopovidona}

El compuesto de povidona yodada (PVP-I) es un antiséptico halogenado utilizado comúnmente de forma tópica, ya sea sobre la piel intacta, las mucosas o heridas, con el objetivo de desinfectar y reducir la concentración de microorganismos en dichos 
tejidos ${ }^{(21)}$. Su uso no se limita al ámbito dental como colutorios o desinfectantes peri operatorios, sino que también es sumamente empleado en la práctica médica común.

En particular, sus agentes compuestos por yodo y polímero polivinilpirrolidona ${ }^{(22)}$ actúan mediante la oxidación de las proteínas y los ácidos nucleicos bacterianos provocando su precipitación; además, desestabiliza las membranas celulares y alteran sus vías metabólicas, disminuyendo de esta manera los requerimientos de oxígeno de los microorganismos, interfiriendo así en su cadena respiratoria por bloqueo del transporte de electrones a través de reacciones electrolíticas con enzimas ${ }^{(23)}$. Por otro lado, su acción virucida contra virus con y sin envoltura lipídica, indicaría su potencial acción frente al nuevo virus SARS-CoV-2 ${ }^{(22,24)}$.

La actividad viricida de los enjuagues depende de la concentración y el tiempo de contacto antiséptico frente al virus SARS-CoV-2 (25). Precisamente, este enfoque es evaluado por Bidra et al. en su estudio in vitro, donde investigaron el tiempo de contacto y concentración óptimos para que las soluciones antisépticas orales de PVP I generen una actividad viricida contra el SARS CoV 2. Se probó concentraciones diluidas de $0,5 \%, 1 \%$ y $1,5 \%$ de PVP I frente a las soluciones de la cepa del virus durante períodos de exposición de 15 y 30 segundos. Los resultados evidencian la eficacia de este antiséptico, que presenta mayores valores de reducción vírica proporcionalmente al tiempo de contacto y a la concentración utilizada ${ }^{(26)}$. En un estudio similar realizado por Pelletier et al., se evaluó las formulaciones antisépticas de enjuague bucal de PVP-I en concentraciones de $1 \%$ al $5 \%$ por un tiempo de $60 \mathrm{~s}$, los ensayos viricidas determinaron la eficacia y la completa inactivación del SARS-CoV-2 producido por estos compuestos ${ }^{(27)}$. Resultados semejantes fueron encontrados por Anderson et al., quienes mediante ensayos de suspensión indicaron que la PVP-I como enjuague bucal al $1 \%$ y spray para la garganta al $0,45 \%$ superan el $99,99 \%$ de actividad viricida contra el SARSCoV-2, con un tiempo de exposición de $30 \mathrm{~s}$ (28)

La concentración y el tiempo de exposición pueden ser mínimos y aun así, tener una eficacia antiviral completa ${ }^{(26,29)}$. Esto fue demostrado en un estudio in vitro realizado por Frank et al., cuyo tiempo mínimo de contacto del antiséptico de PVP-I fue de $15 \mathrm{~s}$ de exposición en las concentraciones de 0,5\%, $1,25 \%$ y $2,5 \%{ }^{(30)}$. Esta afirmación también fue demostrada en diversas publicaciones como la realizada por Hassandarvish et al., en el cual se probó que el enjuague bucal de PVP-I al $1 \%$ muestra una actividad viricida potente y rápida contra el virus SARS-CoV-2 a partir de tiempos de contacto de 15,30 y 60 segundos ${ }^{(31)}$.

La eficacia del compuesto de PVP-I comparados con otros antisépticos orales comúnmente utilizados como el cloruro de cetilpiridinio al $0,07-0,1 \%$, etanol al $21 \%$, peróxido de hidrógeno $(\mathrm{H} 2 \mathrm{O} 2)$ al $1,5 \%-3 \%$ y $\mathrm{CHX}$ al $0,2 \%$ demuestra una superioridad significativa en resultados de inactivación antiviral y reducción de los títulos virales del SARS-CoV-2 en diversas muestras analizadas $(8,9)$

En cuanto a los efectos secundarios por el uso clínico de los enjuagues con PVP-I, no se ha registrado efectos secundarios, así lo demuestra un estudio in vivo realizado por Khan et al., en el cual se evaluó las respuestas $\mathrm{y}$ tolerabilidad en pacientes y personal sanitario que emplearon gotas nasales y realizaron gárgaras con enjuagues bucales de PVP-I al $0,5 \%$ durante $30 \mathrm{~s}$. Se concluyó que este antiséptico estaría provocando la eliminación de las partículas virales presentes en la cavidad oral y nasal; además, se encontró una buena tolerancia por parte de los individuos estudiados frente al uso de la solución de PVPI al $0,5 \%$, ya que no se evidenció respuestas alérgicas, signos de toxicidad, irritación en las mucosas, cambios de coloración, etc ${ }^{(32,33)}$

El tiempo de acción virucida dentro de la cavidad oral necesita de más investigaciones; sin embargo, una investigación realizada por Martínez et al., se analizó el impacto de un enjuague bucal con PVP I sobre la carga viral salival del SARS CoV 2 en cuatro pacientes diagnosticados con COVID 19. Inicialmente, se les tomó una muestra de saliva confirmando la presencia de SARS CoV 2, para que posteriormente los pacientes realizaran un enjuague con $15 \mathrm{ml}$ de PVP-I al $1 \%$ durante 1 min, seguidamente se tomó muestras de saliva en serie a los $5 \mathrm{~min}, 1 \mathrm{~h}, 2 \mathrm{~h}$ y $3 \mathrm{~h}$. Los resultados arrojaron reducción de la carga viral en todas las muestras calculadas mediante un RT PCR, pero cabe resaltar, en dos de los cuatro participantes, la PVP I provocó una caída significativa de la carga viral, que se mantuvo durante al menos 3 horas ${ }^{(34)}$. 


\section{Clorhexidina}

La $\mathrm{CHX}$ es un antiséptico oral muy utilizado en la odontología, principalmente, porque su mecanismo de acción se centra en la reducción de la placa bacteriana y control de la enfermedad periodontal, debido a su amplio espectro antimicrobiano contra diversas bacterias (grampositivas, gramnegativas, aerobias y anaerobias facultativas) y hongos, a través, del incremento de la permeabilidad de su pared celular, originando su lisis ${ }^{(35)}$. Por ello, se ha utilizado como enjuague previo a los procedimientos dentales con el fin de disminuir la cantidad de microorganismos presentes en los aerosoles generados dentro del consultorio dental ${ }^{(3)}$.

Según estudios in vitro, la $\mathrm{CHX}$ también presenta eficacia antiviral, fundamentalmente, en virus con envoltura lipídica, tales como la gripe $A$, el virus del herpes 1, el citomegalovirus, la hepatitis B y la parainfluenza (35); sin embargo, su acción contra el SARS-CoV-2 es un tema controversial, a pesar de ser un virus envuelto. Mientras que la "Guía para el diagnóstico y el tratamiento de la neumonía por el nuevo coronavirus" de la Comisión Nacional de Salud de la República de China menciona que la $\mathrm{CHX}$, como enjuague bucal, no ejerce efectos sobre el SARS-CoV-2 a diferencia de otros enjuagues, cuyo principio activo sea un agente oxidante como el H2O2 o la PVP-I (36); otros autores como Yoon et al. ejecutaron una investigación en dos pacientes hospitalizados por contagio del SARS-CoV-2, donde analizaron la carga viral presente en su saliva mediante la prueba de RT PCR. En el tercer y sexto día de hospitalización, realizaron enjuagues con $15 \mathrm{ml}$ de $\mathrm{CHX}$ al $0,12 \%$ durante 30 s y se observó que la carga viral disminuyó transitoriamente durante las primeras $2 \mathrm{~h}$; sin embargo, posteriormente, volvió a incrementarse. Es importante mencionar que las principales limitaciones de este estudio son el número reducido de pacientes y la ausencia de controles utilizando suero fisiológico ${ }^{(5)}$. Otros estudios, en pacientes críticos, indican que la $\mathrm{CHX}$ ayuda a disminuir la incidencia de neumonía asociada al ventilador de un $24 \%$ a un $18 \%{ }^{(3)}$.

Algunas investigaciones como la de Meister et al. indican que la $\mathrm{CHX}$ sí presenta una actividad antiviral contra el SARS-CoV-2; sin embargo, esta es baja. Su estudio in vitro, comparó ocho enjuagues bucales comerciales, basados en diferentes compuestos activos, contra tres diferentes cepas de SARS-CoV-2 obtenidas de un frotis nasofaríngeo y dos frotis de garganta. La actividad viricida se determinó con una prueba de suspensión cuantitativa durante $30 \mathrm{~s}$ de exposición en condiciones que imitan las secreciones nasofaríngeas y se observó que la $\mathrm{CHX}$ obtuvo un factor de reducción logarítmica de 0,75 ; lo cual indica que la $\mathrm{CHX}$ redujo mínimamente el SARS-CoV2 a comparación de otros compuestos como el cloruro de decualinio, la PVP-I y el etanol aceites esenciales que obtuvieron un factor de reducción logarítmica superior a $3,11^{(9)}$.

En contraste a lo mencionado, Statkute et al. realizaron una investigación in vitro similar, donde evaluaron la capacidad de siete enjuagues bucales, incluida la $\mathrm{CHX}$, para inactivar el SARS-CoV-2 en condiciones similares a la nasofaringe y orofaringe durante una exposición de $30 \mathrm{~s}$. Los resultados mostraron que los enjuagues basados en CPC y etanol al $23 \%$ suprimieron el virus por completo con un factor de reducción logarítmica mayor a 5; caso contrario ocurrió con la $\mathrm{CHX}$ que fue relativamente inactiva con un factor de reducción logarítmica inferior a 2 (37)

La muerte celular asociada a antisépticos puede resultar en una disminución del número de células diana para la infección viral produciendo una aparente disminución de la infectividad viral, que puede confundirse con un potente efecto antiviral. Por ello $\mathrm{Xu}$ et al., evaluaron los efectos de cuatro enjuagues bucales a base de H2O2, PVP-I al 10\%, etanol aceites esenciales y $\mathrm{CHX}$ al $0,12 \%$ sobre la infectividad del virus SARS-CoV-2. Para asegurar que la actividad antiviral no sea consecuencia de la citotoxicidad inducida por el enjuague bucal se determinó la viabilidad celular. Es así que la acción antiviral del H2O2 y de la PVP-I se asoció a su mayor citotoxicidad, esto explica por qué una dilución al $5 \%$ bloqueó completamente la infectividad viral; en cambio, el etanol aceites esenciales y la $\mathrm{CHX}$ fueron menos citotóxicos y, al diluirlos al $5 \%$, tuvieron un efecto supresor moderado sobre el virus; sin embargo, al diluirlos al $50 \%$, bloquearon completamente la infectividad del SARS-CoV-2 (38).

\section{Peróxido de hidrógeno}

Durante mucho tiempo, el $\mathrm{H} 2 \mathrm{O} 2$ ha sido utilizado ampliamente en la práctica 
odontológica como agente principal de productos de aclaramiento dental ${ }^{(39)}$, en menos frecuencia, para el control de placa $y$ enfermedad periodontal. Tarek, quien comparó el efecto antimicrobiano que presenta el $\mathrm{H} 2 \mathrm{O} 2$ y la $\mathrm{CHX}$ en el tratamiento de periodontitis crónica, si bien ambos enjuagues redujeron los signos de una enfermedad periodontal, la $\mathrm{CHX}$ mostró resultados superiores con respecto al $\mathrm{H} 2 \mathrm{O} 2^{(40)}$; sin embargo, en los últimos meses, la aplicación del $\mathrm{H} 2 \mathrm{O} 2$ se ha incrementado por su posible efecto antiviral, lo que ha generado su inclusión dentro de los protocolos de atención odontológica en tiempos de COVID19.

El H2O2 se caracteriza por ser un líquido transparente y no presentar olor. Su mecanismo de acción se basa en su capacidad antioxidante, pues cuando entra en contacto con materias orgánicas, metales y soluciones alcalinas reacciona produciendo radicales libres hidroxilos, capaces de alterar o modificar lípidos, proteínas y ADN. Según Peng et al., el efecto antiviral del H2O2 contra el SARS-CoV-2 se basa en la vulnerabilidad del virus a la oxidación; por lo tanto, las especies reactivas liberadas del $\mathrm{H} 2 \mathrm{O} 2$ podrían degradar su membrana lipídica viral ${ }^{(4)}$.

La actividad viral del $\mathrm{H} 2 \mathrm{O} 2$ fue demostrada en un estudio in vitro, se utilizaron diferentes concentraciones y tiempos de exposición. Los virus analizados fueron el adenovirus tipos 3 y 6 , virus adenoasociado tipo 4 , rinovirus $1 \mathrm{~A}, 1 \mathrm{~B}$ y tipo 7, mixovirus, influenza $A$ y $B$ y el virus respiratorio sincitial. El resultado fue que $\mathrm{H} 2 \mathrm{O} 2$ al $3 \%$ inactivó todos los virus en un tiempo de 1 a 30 min; además, se detectó que, entre todos los virus analizados, influenza y coronavirus fueron los más sensibles ${ }^{(41)}$.

La eficacia antiviral del $\mathrm{H} 2 \mathrm{O} 2$ contra el SARSCoV-2 es muy cuestionable debido a su baja acción viricida en comparación a otros enjuagues bucales ${ }^{(9)}$. Un estudio in vivo realizado en cavidades orales y nasales, evaluó la reducción de SARS-CoV-2 en la nariz y la garganta de ocho portadores a largo plazo, lavando su mucosa con una solución hipertónica y posteriormente con $\mathrm{H} 2 \mathrm{O} 2$ al $3 \%$. Los resultados demostraron que el lavado con $\mathrm{H} 2 \mathrm{O} 2$ puede provocar una interrupción temporal de la carga viral, pero se evalúa que el virus puede continuar replicándose en los estratos mucosos más profundos 0 en el epitelio bronquial ${ }^{(42)}$.
Las concentraciones de $\mathrm{H} 2 \mathrm{O} 2$ tienen un papel fundamental para que un enjuague bucal sea capaz de reducir la carga viral de SARS-CoV-2. Esto fue demostrado en un estudio piloto realizado por Maximilian et al., quienes indicaron que el $\mathrm{H} 2 \mathrm{O} 2$ al $1 \%$ no reduce la carga viral intraoral en sujetos positivos para el SARS-CoV-2; no obstante, el estudio no arrojó ningún dato con respecto a los efectos del enjuague bucal sobre la infectividad de las copias de ARN detectadas ${ }^{(43)}$. Por otro lado, Brida et al. manifestaron que el peróxido de hidrógeno al $1,5 \%$ y al $3,0 \%$ tenía solo una actividad virucida mínima hacia el SARS-CoV2. A pesar que las concentraciones de $\mathrm{H} 2 \mathrm{O} 2$ están en una relación directa con su eficacia antiviral, se debe tener precaución con las altas concentraciones, debido a que pueden producir alteraciones y daños en las células y tejidos de la mucosa oral. Según las directrices actuales de WorkSafe Australia, el H2O2 es considerado una sustancia deletérea cuando presenta concentraciones superiores al $5 \%$.

\section{Cloruro de cetilpiridinio}

El CPC es un antiséptico oral catiónico de amonio cuaternario, que presenta gran solubilidad en agua y en soluciones acuosas. Es utilizado en la odontología, principalmente, por su amplio espectro antimicrobiano, sobre todo, contra levaduras y bacterias grampositivas; además, se recomienda en la reducción de la placa dental y control de la gingivitis como una alternativa en pacientes que manifiestan irritación de la mucosa y manchas asociadas con la $\mathrm{CHX}{ }^{(35,23)}$.

Con respecto a la eficacia antiviral del CPC, algunos estudios in vitro han demostrado su capacidad de inactivación y/o eliminación frente a diversos virus de la influenza, mediante la ruptura de la envoltura lipídica y, de esta manera, se limita la capacidad del virus para ingresar a la célula. Debido a este mecanismo de acción, se ha sugerido su actividad antiviral contra otros virus envueltos como el SARSCoV-2 (25)

Seneviratne et al. realizaron una investigación donde evaluaron la eficacia de tres enjuagues bucales comerciales sobre la reducción de la carga viral del SARS-CoV-2 en la saliva de pacientes contagiados. Para ello, se consideró a 16 pacientes positivos para el SARS-CoV-2 del Hospital de Singapur que fueron asignados 
aleatoriamente en cuatro grupos ( $\mathrm{CHX}, \mathrm{CPC}$, PVP-I y grupo control de agua) y se les pidió que realizaran gárgaras con el enjuague bucal asignado durante 30 segundos, posteriormente, las muestras de saliva se recogieron a los 5 minutos, 3 horas y 6 horas. Los resultados evidenciaron que los enjuagues bucales de PVP-I a las 6 horas y de CPC a los 5 minutos y 6 horas tuvieron un efecto sostenido en la reducción de la carga viral salival en comparación con los pacientes del grupo control de agua; en cambio, la $\mathrm{CHX}$ demostró un efecto variado sobre la carga viral del SARS-CoV-2 ${ }^{(8)}$.

En un estudio in vitro realizado por Muñoz et al., se evaluó la reducción de la infectividad del SARS-Cov-2 en dos enjuagues bucales contenedores de CPC (Perio Aid Intensive Care y Vitis CPC Protect) durante $2 \mathrm{~min}$ de exposición, utilizando la muestra de un hisopado nasofaríngeo de un paciente masculino de 89 años positivo para el virus. Los resultados demostraron que el CPC presenta una actividad antiviral contra el SARS-CoV-2 mediante el bloqueo de la entrada viral o la inhibición de la fusión viral en las células diana. Además, estos enjuagues tienen la capacidad de reducir 1000 veces la infectividad del virus cuando se utilizan en una proporción de 1: 1 durante 2 minutos ${ }^{(46)}$.

Aún se necesitan más estudios comparativos para evaluar la eficacia antiviral; sin embargo, Green et al. realizaron un estudio in vitro, donde los resultados del CPC presentaron una reducción superior al 99,9\% del recuento viral; a comparación de los enjuagues bucales que contenían etanol al $15,7 \%$, sulfato de zinc heptahidratado al $0,2 \%$ y una mezcla de enzimas y proteínas que no demostraron una eficacia antiviral significativa en esta investigación ${ }^{(47)}$.

\section{CONCLUSIÓN}

La literatura consultada sugiere que los diferentes trabajos de investigación in vivo $e$ in vitro revisados, han demostrado que algunos de los principios activos de los antisépticos orales presentan propiedades antivirales, que podrían ser de gran ayuda en la reducción de la carga viral salival del SARS-CoV-2 en pacientes contagiados que acuden a la consulta dental; tal es el caso de la PVP-I que ha demostrado una eficacia superior contra el COVID-19 seguidas del $\mathrm{H} 2 \mathrm{O} 2$, CPC y $\mathrm{CHX}$.
Si bien es cierto, dentro de la literatura revisada, se ha demostrado la eficacia de estos compuestos, cabe resaltar la escasez de estudios clínicos que evalúen el tiempo de duración de eficacia antiviral dentro de la boca de portadores de COVID-19; sin embargo, los enjuagues bucales parecen ser una buena opción preventiva, práctica y segura, mientras se espera lograr un mayor control de la enfermedad a través de la inmunización global. Hasta disponer de más investigaciones clínicas, añadirlos al protocolo de atención odontológico sería recomendable debido a su bajo costo, fácil acceso y uso conocido en el área.

Contribuciones de autoría: GRSS, BHLM, DCBA y MMV, recolectaron la información , redactaron y aprobaron la versión final del manuscrito. MMV realizó la revisión crítica.

\section{Fuente de financiamiento: Autofinanciado.}

Conflicto de intereses: Los autores declararon no tener conflictos de interés.

\section{REFERENCIAS BIBLIOGRÁFICAS}

1. World Health Organization. WHO Coronavirus Disease (COVID-19) Dashboard. 2020.

2. O'Donnell V, Thomas D, Stanton R, Maillard J, Murphy $\mathrm{R}$, Jones $\mathrm{S}$, et al. Potential Role of Oral Rinses Targeting the Viral Lipid Envelope in SARS-CoV-2 Infection. Funct. 2020;1(1): zqaa002.

3. Moosavi M S, Aminishakib, P, \& Ansari M. Antiviral mouthwashes: possible benefit for COVID-19 with evidence-based approach. J. Oral Microbiol. 2020; 12(1):1794363

4. Peng, $X, X u X, L i$ Y, Cheng L, Zhou X, \& Ren B. Transmission routes of 2019-nCoV and controls in dental practice. Int. J. Oral Sci. 2020; 12(1): 16.

5. Yoon JG, Yoon J, Song JY, Yoon SY, Lim CS, Seong $\mathrm{H}$, Noh JY, Cheong HJ, Kim WJ. Clinical Significance of a High SARS-CoV-2 Viral Load in the Saliva. J Korean Med Sci. 2020;35(20):p.195.

6. Galo J. Estructura y composición del SARSCOV-2. Fundación Benalm. 2020; 30: 4-7.

7. Clementini M, Raspini M, Barbato L, Bernardelli $F$, Braga G, et al. Aerosol transmission for SARS CoV 2 in the dental practice. A review by SIdP Covid 19 task force. Oral Dis. 2020 oct 29. doi: 10.1111/odi.13649.

8. Seneviratne CJ, Balan P, Kwan Ki KK, Udawatte NS, Lai D, et al. Efficacy of commercial mouthrinses on SARS-CoV-2 viral load in saliva: randomized control trial in Singapore. Infect. 2020 Dec 14:1-7. doi: 10.1007/s15010-02001563-9. 
9. Meister $\mathrm{T}$, Brüggemann $\mathrm{Y}$, Conzelmann $\mathrm{D}$, et al. Virucidal Efficacy of Different Oral Rinses Against Severe Acute Respiratory Syndrome Coronavirus 2, J. Infect. Dis. 2020; 222 (15): 1289-1292

10. Kaur I, Sharma A, Deepak J, Das A, Sacchidanand S, Sharma R, et al. Coronavirus disease (COVID 19): An updated review based on current knowledge and existing literature for dermatologists. Dermatol Ther. 2020; 33:e13677.

11. Schroter RC. Social distancing for covid-19: is 2 metres far enough? BMJ. 2020;369:m2010.

12. Ge ZY, Yang LM, Xia JJ, Fu XH, Zhang YZ. Possible aerosol transmission of COVID-19 and special precautions in dentistry. J Zhejiang Univ Sci B. 2020:1-8.

13. Xia J, Tong J, Liu M, Shen Y, Guo, D. (2020). Evaluation of coronavirus in tears and conjunctival secretions of patients with SARS CoV 2 infection. J Med Virol. 2020; (92): 589594.

14. Dadlani S. SARS-CoV-2 Transmission in a Dental Practice in Spain: After the Outbreak. Int Dent J, 2020; vol. 2020 Article ID 8828616.

15. Kampf G, Todt D, Pfaender S, Steinmann E. Persistence of coronaviruses on inanimate surfaces and their inactivation with biocidal agents. J Hosp Infect. 2020; 104: 246-251.

16. Aldahlawi $S$ y Afifi I. COVID-19 in Dental Practice: Transmission Risk, Infection Control Challenge, and Clinical Implications. Open Dent J. 2020;14: $348-354$.

17. James R, Mani A. Aerosoles dentales: un peligro silencioso en odontología. Int J Sci Res (Ahmedabad) 2016; 5 (11): 1761-3.

18. Raj G, Suma BS, Mangal G. Aerosol y salpicaduras dentales: un peligro silencioso e implicación en el control de infecciones en odontología. Eur J Pharm Med Res 2019; 6 (2): 603-7.

19. World Health Organization. Questions and Answers About Coronavirus Disease (COVID19). 2020

20. Carraturo F, Del Giudice C, Morelli M, Cerullo V, Libralato G, Galdiero E, et al. Persistence of SARS-CoV-2 in the environment and COVID-19 transmission risk from environmental matrices and surfaces. Environ Pollut. 2020; 265: 115010.

21. Challacombe S, Kirk-Bayley J., Sunkaraneni V. et al. Povidona yodada. Br Dent J. 2020; 228: 656-657.

22. Río-Carbajo L y Vidal P. Tipos de antisépticos, presentaciones y normas de uso. Medicina Intensiva, 2020;43 (S1): 7-12.

23. Carrouel F, Gonçalves LS, Conte MP, et al. Antiviral Activity of Reagents in Mouth Rinses against SARS-CoV-2. J Dent Res.2020; 100(2): 124-132.

24. Lepelletier D, Maillard JY, Pozzetto B, Simon A. Povidone lodine: Properties, Mechanisms of Action, and Role in Infection Control and
Decolonization. Antimicrob Agents Chemother. 2020; 64(9):e00682-20.

25. Herrera D, Serrano J, Roldán S. et al. Is the oral cavity relevant in SARS-CoV-2 pandemic?. Clin Oral Invest. 2020; 24: 2925-2930.

26. Bidra, AS, Pelletier, JS, Westover, JB, Frank S, Brown SM and Tessema B .Rapid In Vitro Inactivation of Severe Acute Respiratory Syndrome Coronavirus 2 (SARS CoV 2) Using Povidone lodine Oral Antiseptic Rinse. J Prosthodont. 2020; 29: 529-533.

27. Pelletier JS, Tessema B, Frank S, Westover JB, Brown SM, Capriotti JA. Efficacy of Povidonelodine Nasal and Oral Antiseptic Preparations Against Severe Acute Respiratory SyndromeCoronavirus 2 (SARS-CoV-2). Ear Nose Throat J. 2020 Apr;100(2_suppl):192S-196S.

28. Anderson DE, Sivalingam V, Kang A E Z. et al. Povidone-lodine Demonstrates Rapid In Vitro Virucidal Activity Against SARS-CoV-2, The Virus Causing COVID-19 Disease. Infect Dis Ther, 2020; 9: 669-675.

29. Kalsi, H., Edwards, D. PVP-I mouth rinse in dental practice. Br Dent J, 2020: 229, 736.

30. Hassandarvish $\mathrm{P}$, Tiong $\mathrm{V}$, Mohamed $\mathrm{N}$, et al. In vitro virucidal activity of povidone iodine gargle and mouthwash against SARS-CoV-2: implications for dental practice. Br Dent J; 2020 dec 10:1-4.

31. Frank S, Brown SM, Capriotti JA, Westover JB, Pelletier JS, Tessema B. Eficacia in vitro de un antiséptico nasal de povidona yodada para la inactivación rápida del SARS-CoV-2. JAMA Otolaryngol Head Neck Surg. 2020; 146 (11): 1054-1058.

32. Khan MM, Parab SR and Mandar P. Repurposing $0.5 \%$ povidone iodine solution in otorhinolaryngology practice in Covid 19 pandemic. Am J Otolaryngol. 2020;41(5):102618.

33. Bo Liang, Xudong Y, Gang W. In-Vivo Toxicity Studies and In-Vitro Inactivation of SARS-CoV2 by Povidone-iodine In-situ Gel Forming Formulations. bioRxiv. 2020 May 20:2020.05.18.103184.

34. Martínez L, Diz P, Pérez MT, et al. Is povidone iodine mouthwash effective against SARS CoV 2? First in vivo tests. Oral Dis. $2020 \mathrm{Jul}$ 2:10.1111/odi.13526. doi: 10.1111/odi.13526.

35. Vergara A y Castro C. The Use of Mouthwashes against COVID-19 in Dentistry. $\mathrm{Br} J$ Oral Maxillofac Surg. 2020; 58 (8): 924927.

36. National Health Commission of the ROC. Guide for the diagnosis and treatment of pneumonia caused by the new coronavirus. Pekín: National Health Commission of the ROC. 2020.

37. Statkute E, Rubina A, O'Donnell V, Thomas D, Stanton R. Brief Report: The Virucidal Efficacy of Oral Rinse Components Against SARS-CoV2 In Vitro. BioRxiv. 2020; 11(13): 1-10. 
38. Xu C, Wang A, Hoskin E, Cugini C, Markowitz $\mathrm{K}$, Chang $\mathrm{T}$, et al. Differential effects of antiseptic mouth rinses on SARS-CoV-2 infectivity in vitro. BioRxiv. 2020; 12(1): 1-33.

39. Roncal RJ, Tay-Chu-Jon LY. Aclaramiento Dental con Enjuagues de Libre Venta que Contienen Peróxido de Hidrógeno. Int. J. Odontostomat. 2018; 12(2):121-124.

40. Rashed HT. Evaluation of the effect of hydrogen peroxide as a mouthwash in comparison with chlorhexidine in chronic periodontitis patients: A clinical study. J Int Soc Prev Community Dent. 2016;6(3):206-212.

41. Mentel' R, Shirrmakher R, Kevich A, Drězin RS, Shmidt I. Virus inactivation by hydrogen peroxide. Voprosy Virusologii. 1977; (6):731733.

42. Capetti AF, Borgonovo F, Morena V, Lupo A, Cossu MV, Passerini M, et al. Short term inhibition of SARS CoV 2 by hydrogen peroxide in persistent nasopharyngeal carriers. J Med Virol. 2021;93(3):1766-69.

43. Gottsauner MJ, Michaelides I, Schmidt B, Scholz KJ, Buchalla W, Widbiller M, et al. A prospective clinical pilot study on the effects of a hydrogen peroxide mouthrinse on the intraoral viral load of SARS-CoV-2. Clin Oral Invest. 2020; (24): 3707-3713.

44. Bidra AS, Pelletier JS, Westover, JB, Frank S, Brown SM, Tessema B. Comparison of In Vitro Inactivation of SARS CoV 2 with Hydrogen Peroxide and Povidone lodine Oral Antiseptic Rinses. J Prosthodont. 2020; (29): 599-603.

45. Walsh LJ. Safety issues relating to the use of hydrogen peroxide in dentistry. Aust Dent J.2000; (45): 257-269.

46. Muñoz J, Perez D, León R, Blanc V, Gispert J, Clotet $\mathrm{B}$, et al. Cetylpyridinium chloridecontaining mouthwashes reduce in vitro SARSCoV-2 infectivity. BioRxiv. 2020; 12(21): 1-13.

47. Green A, Roberts G, Tobery T, Vincent C, Barili $\mathrm{M}$, Jones $\mathrm{C}$. In vitro assessment of the virucidal activity of four mouthwashes containing Cetylpyridinium Chloride, ethanol, zinc and a mix of enzyme and proteins against a human coronavirus. BioRxiv. 2020; 10(28): 1-6.

Shirley Guerra Robalino

ORCID iD: (1) https://orcid.org/0000-0002-6806--3759

shirley.guerra@unmsm.edu.pe

Lisbeth Brañez Huaman

ORCID iD: (1) https://orcid.org/0000-.00021-7247--7455

lisbeth.branes@unmsm.edu.pe

Brenda Dominguez Calle

ORCID iD: () https://orcid.org/0000-0003-0738-8514

brenda.dominguez@unmsm.edu.pe

Manuel Mattos Vela

ORCID iD: 다 https://orcid.org/0000-0002-5701-1961

mmattosv@unmsm.edu.pe

Copyright $($ L La revista. La revista Kiru es publicada por la Facultad de Odontología de la Universidad de San Martín de Porres, en Lima, Perú. 